\title{
A Maintenance Management Model. Upgrading and Experimentation
}

\author{
Maria Azzalin $^{1}$ and Massimo Lauria ${ }^{2}$ \\ ${ }^{1}$ Dipartimento dArTe, di Architettura e Territorio, Università degli studi Mediterranea di Reggio \\ Calabria, via Melissari, Feo di Vito, 89124 Reggio Calabria, maria.azzalin@unirc.it \\ ${ }^{2}$ Dipartimento dArTe, di Architettura e Territorio, Università degli studi Mediterranea di Reggio \\ Calabria, via Melissari, Feo di Vito, 89124 Reggio Calabria, mlauria@unirc.it
}

\begin{abstract}
The paper deals with the first results of the activities of BIG Building Innovative Governance srl, Academic Spin-Off and Innovative Start Up, which provides smart services for Building Maintenance and Facility Management also launching circular $R \& D$ actions in the relative reference areas. The contribution introduces some actions actually in progress geared to upgrading the Maintenance Management Model, M3, specifically aimed at managing the life cycle of buildings.

The current stage of development corresponds to a TRL 4. TRL 8 is that expected by the end of 2020. Characterized by interconnectivity and scalability, the Maintenance Management Model is a dynamic, collaborative and implementable system, whose architecture consists of three separated but strongly interconnected devices: an information interface system, a collaborative platform, a remote cloud. An ICT network infrastructure able to activate using BIM models (IFC and COBie standards) circular information workflows between all operators and/or users involved in Maintenance and Facility Management processes. It allows the development and/or implementation of information management and sharing models based on Open Data and Semantic Web. Its use will also promote shared lexicons and the circulation of knowledge within a holistic process of managing information from and for Maintenance. The use of BIM models and the possibility of collecting and managing a large amount of data will be oriented to the structuring of information feedback databases according to ISO 15686 guidelines. In this way, available information can be usefully transferred in life cycle assessments and service life prediction of materials and components.
\end{abstract}

Keywords: Facility Management, Information System, Maintenance Management Model, Operation\&Maintenance, Service Life Planning.

\section{Introduction}

BIG srl is a spin-off of the Mediterranean University of Reggio Calabria, as well as an enterprise registered in the list of innovative Startups.

It operates in the field of technological innovation exploiting, in line with the operational trend of Industry 4.0 and the potentials of Information Communication Technology, ICT; also provides Innovative Integrated Services characterized by technical-scientific nature and high technological value oriented to the construction market and in particular to the Facility Management, FM; develops R\&D actions in the sectors focused on Smart Building and Smart Cities drivers. To implement its mission, it assumes as central the interactions between technological capital (infrastructure and technology), human capital (researchers, companies, professionals, users, etc.), administration (institutions, universities, managers, etc.) and real estate (public and/or private heritage).

BIG srl is currently engaged in the experimentation of an innovative governance system for real estate assets, Maintenance Management Model, M3. 
The service offered through the proposed Maintenance Management Model answer for a primary need of the construction sector as well as of the research one: to increase the effectiveness, efficiency, circulation of information and communication between the operators involved in the management and operation \& maintenance practices whose activities presuppose multidisciplinary approaches and great structured data availability.

This primary need is today perceived as immanent criticality for the construction sector. Its effects are felt with concern by technicians and workers, and at the same time, shape a crucial issue that manifests itself in all its severity due to the unexpectedly increasing costs - economic and social - connected with the lack of maintenance of infrastructures, buildings and plants. (World Economic Forum, 2016)

O\&M operating and maintenance costs, which are generally neglected during the design phase, generally amount to more than half of the total costs of the building's life cycle (BecerikGerber et al., 2012). However, more and more often they represent cost items linked to the inefficiency of choices in the design phase or to mistakes made during the construction phase.

The authors of the paper are among the founders of BIG srl and have been working on the issue for a long time in the scientific and academic field. (Lauria, 2003, Azzalin et al. 2005, Lauria and Azzalin, 2006, Azzalin, 2007, Lauria and Azzalin, 2007, Lauria at al. 2015, Lauria and Azzalin, 2019, Azzalin, 2019)

In addition to the skills of each founding members, BIG srl avails itself of the expertise recognized to the two industrial partners:
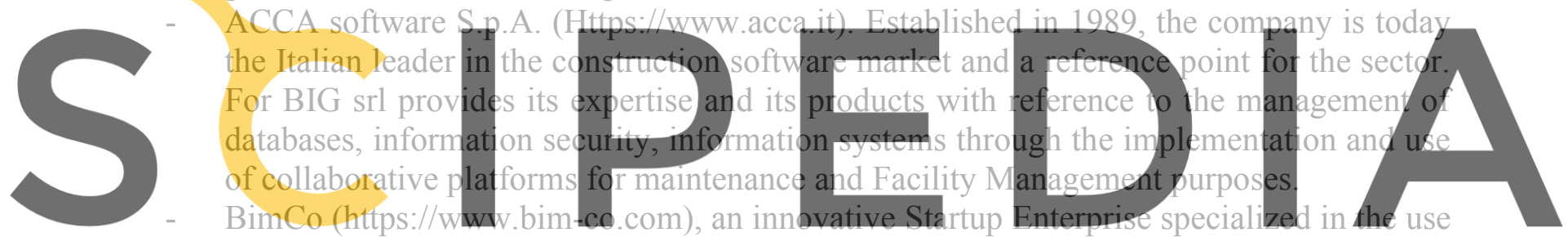

of IT methods and tools for interoperability such as BIM, Building Information Modeling.

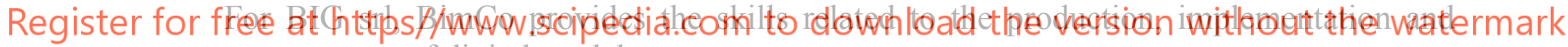
management of digital models.

\section{Background}

The service life and management of a building in its life cycle always combines the terms "costs", "efficiency", "maintainability" and "sustainability" with the planning activity. In this context, Facility Management is defined as an integrated approach oriented to the operation, maintenance, improvement and adaptation of real estate and infrastructure in order to meet the primary objectives of the occupants, owners and managers (Atkin and Brooks, 2009).

Its importance and relevance, assumed by BIG srl as a corporate policy, refers to and is framed, in numerous regulatory actions, scientific research, market trends, both internationally and nationally. The FM involves a relevant field of interest, requires numerous data and information and presupposes multidisciplinary approaches.

The available information and data, whether they concern new or existing construction, are almost never structured to be effectively used in the O\&M activities, and not sufficient.

In practice, inefficiencies, disconnected processes and different degrees of dysfunction correspond to this gap. 
In the recent past, and even today, data and information for FM are organized and managed by Computerized Maintenance Management System and Computer Aided Facility Management (CMMS and CAFM), Electronic Document Management Systems (EDMS), Building Automation Systems (BAS), etc.

However, these processes are subject to errors (Becerik-Gerber et al., 2012).

Today, in general, in the face of still limited use of open standards for structuring and transfer of information, the specific need for open systems and standardized data libraries and specifically declined is added (BIFM, 2012). The availability of open standards, Industrial Foundation Classes, IFC (ISO 16739-1:2018) and data specifications, Construction Operations Building information exchange (COBie-NBIMS-US-V3.4:2015), the diffusion of Building Information Modeling (BIM) methodologies and the adaptation of legacy systems represent the new frontier for the research and standardization challenges. (Kassem et al., 2015a). Several countries, including the United Kingdom in the first place, have introduced and prescribed the use of interoperability tools based on open data, open standards (IFC) and data specifications (COBie) as formats and information exchange methods between the project delivery phases and the use phase of the building (Kassem et al., 2013).

As part of the aforementioned policies, in the United Kingdom the PAS 1192-3:2014 standard (BSI 2014a) is a reference for the structuring of data aimed at the management phase. It introduced an information management methodology based on openBIM standards and data specifications (COBie) connected with BS 8544:2013 (BSI 2013), relating to life cycle costs during the maintenance phase of buildings.

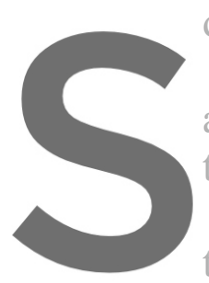
Currently, BuildingSMART deals with the open standards
aim of defining languages shared between the various operatcris
the building process and the life eyele of the assets. (Atkin and
Further research areas condern the COBie data exchange
the British industrial standard BS 1192-4:2014(BSI 2014b) is

IFC and COBie are also employed in the context of standardization actions relating to

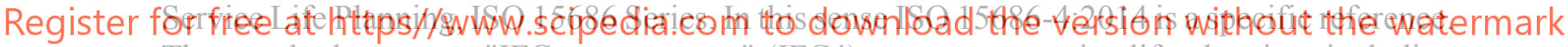
The standard proposes "IFC property sets" (IFC4) to support service life planning, including information on the durability of materials, semi-finished products and components. Moreover, the factors that affect durability as introduced in ISO 15686-2:2012, environmental impacts in ISO 15686-6:2004 (at now withdrawn), and Life Cycle Costing (LCC) according to the contents of ISO 15686-5:2017. This thus confirms a strong interrelationship between the LCC assessments, the costs in the usage phase of the building and the decision-making processes aimed at optimizing the Operation \& Maintenance phase (Fu et al., 2007, BSRIA, 2009). In other words, in a general context of life cycle management, the BIM based interoperability systems based on open data (IFC standards and COBie) can provide the information needed for planning, execution and management of maintenance actions allowing this information to be structured and kept in an organized management system (CIC, 2012). This system, which can be implemented and accessed over time, will be both a repository and a source of feedback information available at the design stage (Volk et al., 2014).

In short, the essential background introduced above and, more specifically, OpenBIM for FM, the interactions between IFC and COBie and their applications for the management of FM processes and the service life planning (Maxwell, 2005, Kassem et al., 2015b) configure the assumptions from which the R\&D actions of BIG srl and the Upgrading of M3 start. 


\section{Upgrading M3}

Currently the upgrade of the Maintenance Management Model, M3 specifically aimed at managing the life cycle of buildings is being implemented thanks to a public financing from the Calabria Region according to the Public Call of POR Calabria ERDF 2014/2020 Action 1.4.1 Support for the creation of innovative micro-enterprises Startup and Spinoff of research.

M3 is aimed at the assistance and smart accompaniment for building maintenance and real estate assets Facility Management activities.

Developed starting from a PhD research (Melchini, 2015), the subsequent definition and implementation of M3 has received significant validation resulting in being the winner and finalist of some contests for innovative business ideas (Coopstartup Calabria Ricomincio da T (r)E, 2016; StartcupCalabria, 2016, national finalist of Startup Europe Awards, 2017).

M3 is an ICT network infrastructure that will allow the development and/or implementation of information management and sharing models based on Open Data, as well as the definition and continuous verification of operational requirements (BSRIA, 2009) among the various operators involved in the whole cycle of life of a building. From the design phase (clients, designers, structural engineers, installers, etc.) and construction (companies and producers suppliers of materials and components) to management (maintenance personnel, etc.) and disposal phases; and between all operators and the final users themselves (Figure 1).
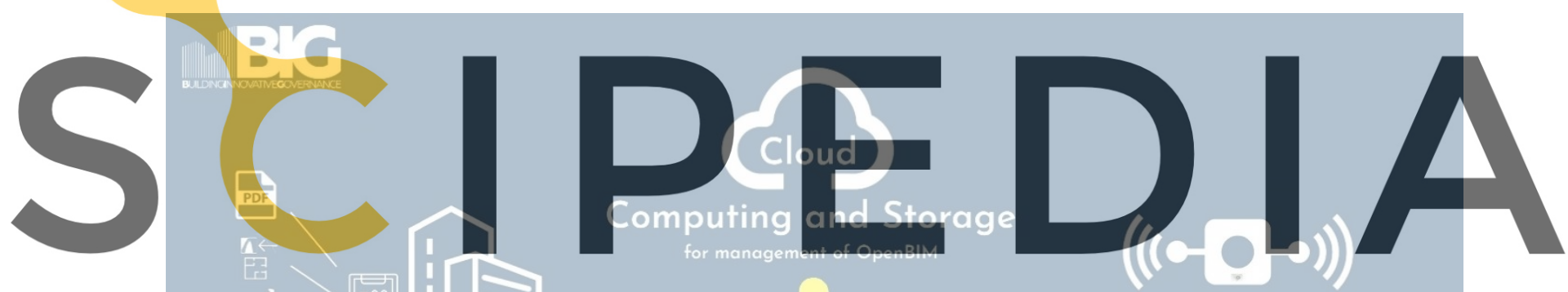

Register for free at https//www.scipedia.com to download the version without the watermark

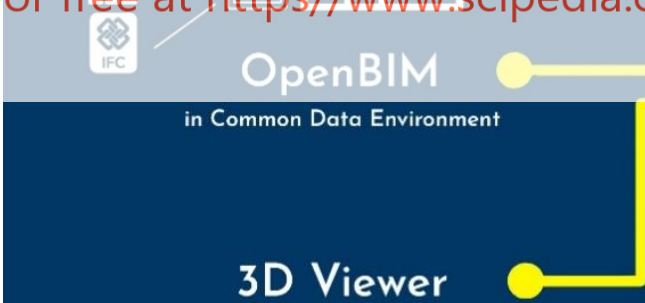

usage in Virtual and Augmented Reality
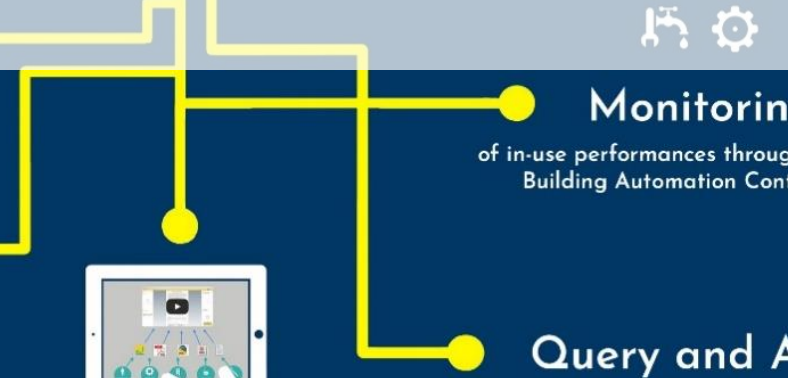

\section{Monitoring}

of in-use performances through Domotic and Building Automation Control System

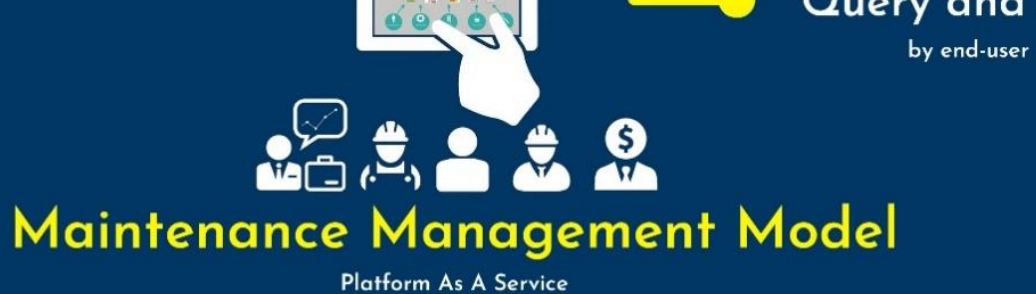

Platform As A Service

Figure 1. M3 Maintenance Management Model Architecture. 
The objective is to support the decision-making process relating to the building management phase through an Information Modeling Asset (AIM) based on openBIM standards (IFC) and specifications on the data structure (COBie).

The structuring of the requirements that allow the definition of the AIM is based on the use of the ISO methodology, Information Delivery Manual (IDM) in ISO 29481-1:2016. A general methodology for defining the requirements of the FM format. In particular, IDM makes possible mapping and describing information processes throughout the life cycle of a building, maintaining links with each of the different phases in which information has been generated, exchanged, controlled and used.

Assumed as an initial development stage of the Management Model, a TRL 4 "low reliability prototype that can be built to demonstrate the technology and its function in the laboratory", a specific Business Development Plan and R\&D is being implemented to allow:

- The realization of the engineering functioning model, corresponding to a TRL 6 . In the specific case, the expected result is equivalent to an engineering prototype whose technology realizes a first connection level of the three apparatuses that make up the architecture of the Maintenance Management Model: an Information System (AIM); a collaborative platform (usBIM.platform by ACCA Software spa); a Cloud Computing.

The upgrade to TRL 8 corresponding to a complete prototype system.

Its experimentation, verification and validation (O.R.R., Operational Readness Review) Its marketing.

On a technical level.

management relating dossiers will allow, thro and COBie format), accessibility, employı The availability of a
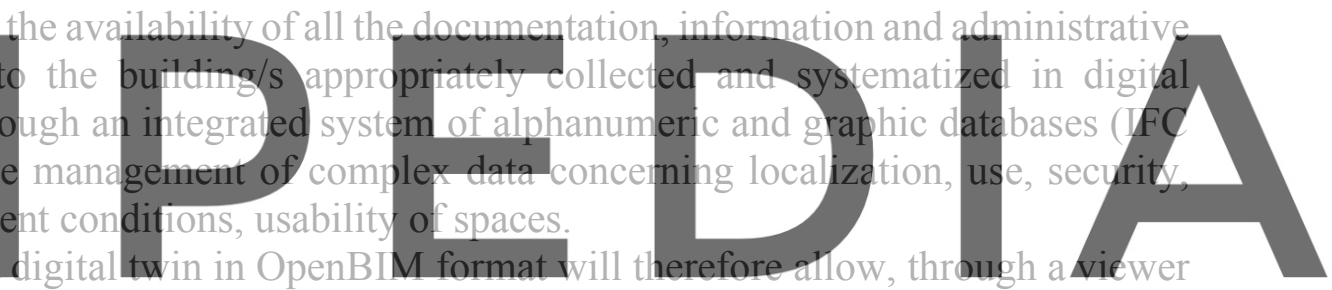

and the interaction in Virtual and Augmented Reality modes, the following visualization:

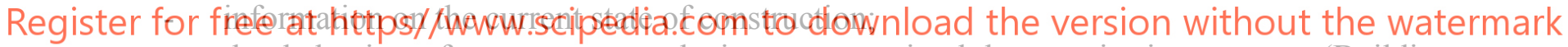
the behavior of component and sistem transmitted by monitoring system (Building Automation home automation systems);

- the location and degree of severity of active fault and possible operational scenarios for the purpose of the intervention.

The partner ACCA spa, leader in the OpenBIM at national level, has made the usBIM.platform collaborative platform technology available for implementation in the direction described. With usBIM.platform is possible to manage the OpenBIM models (IFC standards and COBie specifications) of each type (architecture, plants, energy, structures, construction site and maintenance) in a single Data Sharing Environment (ACDat) or Common Data Environment (CDE ). The related plug-in is being tested through a pilot application to the case study identified in a portion of the building asset of Mediterranean University of Reggio Calabria. In particular, the "usage scenario" of the system is the evaluation of IFC4 and COBie 2.4 and some of their enabling technologies.

The ongoing experimentation and the subsequent M3 implementation prefigure some main expected results. Evaluating IFC and COBie support in meeting the information requirements for the creation of the management activity register and proposing ways to implement and extract maintenance requirements respectively in and from BIM models. 
The actions undertaken also promote shared lexicons and the circulation of knowledge within an interdisciplinary process of managing information from and for Maintenance.

The use of BIM models and the possibility of collecting and managing a large amount of data will be used as a source of information for service life planning. In particular, they will be oriented to the structuring of information feedback databases according to ISO 15686-7:2017 guidelines related to service life prediction of materials and components.

\section{Conclusions}

Although the results of the research in these areas refer to experiments that bring to the identification of some general OpenBIM requirements capable of supporting building maintenance activities (Hallberg and Tarandi, 2011, Becerik-Gerber et al., 2012, CIC, 2012, Motamedi et al., 2014). To date, detailed studies and systematic evaluations of the IFC and COBie standards applied to FM are still lacking. In fact, it emerges from the literature that these, together with the available software support tools, are still inadequate for the management of the life cycle during the maintenance phase. (Kassem et al., 2015a)

Furthermore, there are no widespread studies on the development of OpenBIM for FM and in particular research aimed at understanding "how" and "if" IFC and COBie can be effectively integrated to support FM processes.

Limits and criticalities that represent the areas of development and implementation of research in general and that related to the upgrade phase of M3 in particular but also of future

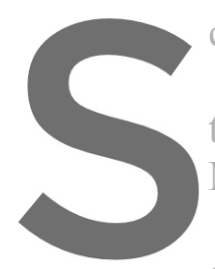
commitments in the world of standardization and ICT. In a perspective that together: quality, duration, Management Model, M On the one hand, a to of innovative information sharing processes $(0 p c$
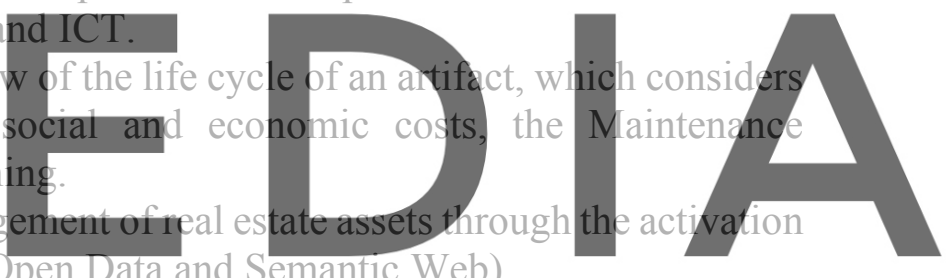

On the other hand, it is evident that to effectively support decision-making processes in the

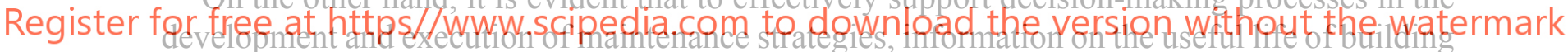

components is fundamental (Hovde and Moser, 2004) and should be taken into consideration from the earliest stages of planning (Marteinsson, 2005).

According to this vision M3 is beginning to look as a privileged "observatory" of the phenomena that characterize building systems over time, their operation and their use. Therefore, it appears functional for oriented collection of feedback data relating to the behavior of materials and components in specific contexts according to ISO 15686-7:2017 and as clearly expressed by the same ISO 15686-4:2014.

\section{ORCID}

Massimo Lauria: http://orcid.org/0000-0003-4363-6642

Maria Azzalin: http://orcid.org/0000-0002-4890-9251

\section{References}

Atkin, B. and Brooks, A. (2009). Total Facilities Management, 3rd edn, United Kingdom.

Azzalin, M., Nesi, A., Lannutti, C., Lauria, M., Nicosia, C. and Pastura, F., (2005). Standards and Tools for the Guarantee of the Reliability of the Intermediate Product in Building, Proceeding of 10 International Conference on Durability of Building Materials and Components. 
Azzalin, Maria, (2007). “Applicabilità del Factor Method per la valutazione della service life di materiali e componenti nel progetto dell'esistente. Manutenzione e Fattore manutentivo", Tesi di Dottorato in Tecnologia dell'Architettura, XVIII ciclo 2003/2006 Università degli Studi Mediterranea di Reggio Calabria.

Azzalin, M., (2019). Manutenzione e valutazione della sostenibilità ambientale nelle costruzioni. Una sinergia possibile tra presente e futuro, in Atti del Convegno Internazionale SBE19 - Sustainable Built Environment Conference, May 16th - 17th 2019, Scilla (RC) Italia.

Becerik-Gerber, B., Jazizadeh, F., Li, N. and Calis, G. (2012). Application Areas and Data Requirements for BIMEnabled Facilities Management, Journal of Construction Engineering and Management, vol. 138, no. 3.

BIFM (2012). BIM and FM: Bridging the gap for success, British Institute of Facilities Management, Bishop's Stortford, Hertfordshire, UK.

BSI (2014a). PAS 1192-3: Specification for information management for the operational phase of assets using building information modelling. BSI Standards Limited

BSI (2014b). BS 1192-4: Collaborative production of information Part 4: Fulfilling employer's information exchange requirements using COBie - Code of practice. BSI Standards Limited

BSI (2013). BS 8544: Guide for life cycle costing of maintenance during the in-use phases of buildings. BSI Standards Limited

BSRIA (2009). The Soft Landings Framework, BSRIA.

Cabinet Office (2012). COBie Data Drops

CIC (2012), Building Information Modeling Planning Guide for Facility Owners

Fu, C., Tah, J. and Aouad, G. (2007). The Life cycle Costing Simulation for Building Construction and Maintenance in nD Modelling, Building Simulation 2007, pp. 1580.

Hallberg, D. and Tarandi, V. (2011). On the use of 4D BIM and visualization in a predictive life cycle management system for construction works, Journal of Information Technology in Construction (ITcon), vol. 16, pp. 445.

Hovde, P. and Moser, K. 2004, Performance Based Methods for Service Life Prediction, International Council for Research and Innovation in Building and Construction (CIB).

ISO/TC 59/SC 14 (2004). 15686-6: Buildings and donstructed assets — Service life planning - Part 6:
Procedures for considering environmental impacts.
ISO/TC 59/SC 14 (2012). 15686-2: Buildings and constructed assets — Service life planning — Part 2: Servide
life prediction procedures.
ISO/TC 59/SC 14 (2014). ISO 15686-4: Buildings and constructed assets - Service Vife planning - part 4:
Service life planning using Building Information Modelling.

ISO/TC 59/SC 14 (2017). ISO 15686-5: Buildings and constructed assets - Service life planning — Part 5: Life-

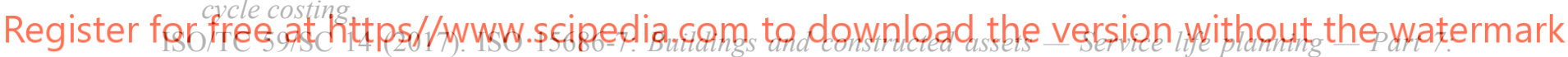
Performance evaluation for feedback of service life data from practice.

ISO/TC 59/SC 13 (2016). ISO 29481-1: Building information models - Information delivery manual - Part 1: Methodology and format.

ISO/TC 59/SC 13 (2018). 16739-1: Industry Foundation Classes (IFC) for data sharing in the construction and facility management industries - Part 1: Data schema.

Kassem, M., Succar, B. and Dawood N. (2013). A proposed approach to comparing the BIM maturity of countries, Proceedings of the CIB W78 2013: 30th International Conference, Beijing, China, 9-12 October

Kassem, M., Vukovic, V., Dawood N. and Patacas, J., (2015a). BIM for Facilities Management: evaluating BIM standards in asset register creation and service life planning, Electronic Journal of Information Technology in Construction.

Kassem, M., Kelly, K., Dawood, N., Serginson, M. and Lockley, S. (2015b), BIM in Facilities Management applications: a case study of a large university complex, Built Environment Project and Asset Management, Vol. 5(3).

Lauria, M., (2003). Evaluation of flat roofs reliability, in: Daniotti B., Management of Durability in the Building Process, Maggioli Editore, Rimini.

Lauria, M., Azzalin, M., (2006) Service Life Estimation and Maintenance in building design. A practical view on application of Factor Method, Proceedings of 3rd World Congress of Maintenance 18th EuroMaintenance.

Lauria, M. and Azzalin, M., (2007) Manutenzione e valutazione della service life nel progetto dell'esistente. Un'applicazione del Factor Method, in La cultura della manutenzione nel progetto edilizio e urbano, LetteraVentidue Edizioni, Siracusa. 
Lauria, M., Milazzo and L., Modaffari, C., (2015). Operational tools for maintenance and renewal of school buildings patrimony, Techne n.9, FUP, Firenze.

Lauria M. and Azzalin M., (2019) Project and maintainability in the era of Industry 4.0, Techne n.18, FUP, Firenze Maxwell, J.A. (2005) Qualitative research design: An interactive approach. 2nd edn. Thousand Oaks, CA: Sage Publications.

Marteinsson, B. (2005) Service life estimation in the design of buildings: A development of the factor method. PhD thesis. KTH Research School.

Melchini, T. (2015) Il Building Information Modelling (BIM). Innovazione dei processi progettuali, realizzativi e gestionali nella governance del patrimonio residenziale pubblico, $\mathrm{PhD}$ Thesis, Università Mediterranea di Reggio Calabria

Motamedi, A., Hammad, A. and Asen, Y. 2014, "Knowledge-assisted BIM-based visual analytics for failure root cause detection in facilities management", Automation in Construction, vol. 43.

World Economy Forum, Boston Consulting Group, (2016). Shaping the Future of Construction. A Breakthrough in Mindset and Technology

Volk, R., Stengel, J. and Schultmann, F. 2014, "Building Information Modeling (BIM) for existing buildings Literature review and future needs", Automation in Construction, vol. 38.
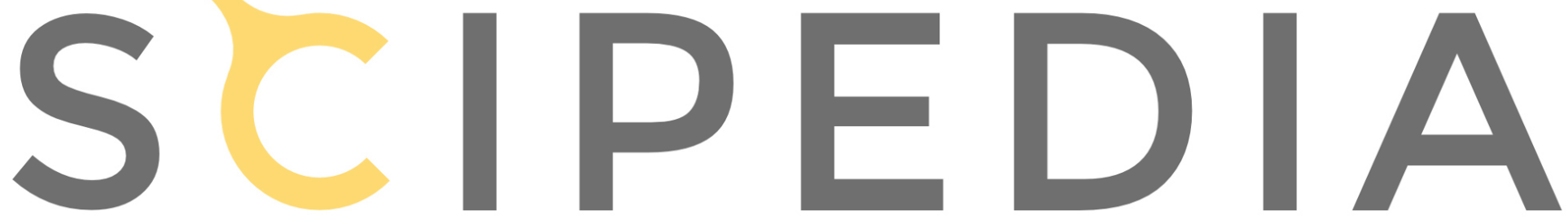

Register for free at https//www.scipedia.com to download the version without the watermark 